\title{
The YvfTU Two-component System is involved in plcR expression
} in Bacillus cereus

\author{
Julien Brillard*1, Kim Susanna ${ }^{2,4}$, Caroline Michaud ${ }^{1}$, Claire Dargaignaratz ${ }^{1}$, \\ Michel Gohar ${ }^{3}$, Christina Nielsen-Leroux ${ }^{3}$, Nalini Ramarao ${ }^{3}$, Anne- \\ Brit Kolst $\varnothing^{2}$, Christophe Nguyen-the ${ }^{1}$, Didier Lereclus ${ }^{3}$ and \\ Véronique Broussolle ${ }^{1}$
}

Address: ${ }^{1}$ UMR408, Sécurité et Qualité des Produits d'Origine Végétale, INRA, Université d'Avignon, F-84000 Avignon, France, ${ }^{2}$ Department of Pharmaceutical Biosciences, School of Pharmacy, University of Oslo, Norway, ${ }^{3}$ INRA, Unité de Génétique Microbienne et Environnement, La Minière, Guyancourt, France and ${ }^{4}$ Department of Molecular Genetics, University of Groningen, the Netherlands

Email: Julien Brillard* - brillard@avignon.inra.fr; Kim Susanna - K.A.Susanna@rug.nl; Caroline Michaud - michaud@avignon.inra.fr; Claire Dargaignaratz - dargaign@avignon.inra.fr; Michel Gohar - gohar@jouy.inra.fr; Christina Nielsen-Leroux - christina.nielsen@jouy.inra.fr; Nalini Ramarao - nalini.ramarao@jouy.inra.fr; Anne-Brit Kolstø - a.b.kolsto@farmasi.uio.no; Christophe Nguyenthe - nguyenth@avignon.inra.fr; Didier Lereclus - Didier.Lereclus@jouy.inra.fr; Véronique Broussolle - broussol@avignon.inra.fr

* Corresponding author

Published: 16 October 2008

BMC Microbiology 2008, 8:183 doi:10.1/86/147|-2180-8-183
Received: 29 May 2008

Accepted: 16 October 2008

This article is available from: http://www.biomedcentral.com/I47/-2/80/8//83

(C) 2008 Brillard et al; licensee BioMed Central Ltd.

This is an Open Access article distributed under the terms of the Creative Commons Attribution License (http://creativecommons.org/licenses/by/2.0), which permits unrestricted use, distribution, and reproduction in any medium, provided the original work is properly cited.

\begin{abstract}
Background: Most extracellular virulence factors produced by Bacillus cereus are regulated by the pleiotropic transcriptional activator PIcR. Among strains belonging to the $B$. cereus group, the plcR gene is always located in the vicinity of genes encoding the YvfTU two-component system. The putative role of YvfTU in the expression of the PIcR regulon was therefore investigated.

Results: Expression of the plcR gene was monitored using a transcriptional fusion with a lac $Z$ reporter gene in a yvfTU mutant and in its B. cereus ATCC 14579 parental strain. Two hours after the onset of the stationary phase, a stage at which the PlcR regulon is highly expressed, the plcR expression in the yvfTU mutant was only $50 \%$ of that of its parental strain. In addition to the reduced plcR expression in the yvfTU mutant, a few members of the PIcR regulon showed a differential expression, as revealed by transcriptomic and proteomic analyses. The virulence of the yvfTU mutant in a Galleria mellonella insect model was slightly lower than that of the parental strain.

Conclusion: The YvfTU two-component system is not required for the expression of most of the virulence factors belonging to the PlcR regulon. However, YvfTU is involved in expression of plcR, a major regulator of virulence in $B$. cereus.
\end{abstract}

\section{Background}

Bacillus cereus is a Gram-positive, rod-shaped, motile and spore-forming bacterium with opportunistic pathogen properties in human, causing local and systemic infections. B. cereus is mostly observed as a causative agent of food poisoning. This species belongs to the $B$. cereus group that includes the closely related species Bacillus anthracis, Bacillus thuringiensis, Bacillus weihenstephanensis, Bacillus mycoides and Bacillus pseudomycoides [1,2]. B. cereus produces several secreted proteins, including enterotoxins, 
cytolysins, phospholipases and proteases that may contribute to B. cereus pathogenicity. Expression of most of these virulence factors is controlled by the pleiotropic transcriptional activator PlcR [3-5]. This global regulator contributes to $B$. cereus virulence in mice, in insects [6] and to rabbit endophthalmitis [7]. Expression of the PlcR regulon starts at the onset of the stationary phase of growth [8]. It results from a cell-cell communication system that requires PapR, a peptide exported and reimported in the bacterial cell as a mature form via an oligo-peptide permease $[9,10]$. The PlcR-PapR active complex binds a DNA target site, designated as the PlcR box, thus activating transcription of the PlcR regulon genes $[3,10]$.

Bacteria recognize and respond to a variety of environmental stimuli using various signal transduction mechanisms, including two-component systems (TCS) [11]. TCS are characterized by a histidine kinase (HK) sensor coupled with a cognate response regulator. Perception of a particular stimulus by the HK leads to its autophosphorylation. The phosphoryl group is then transferred to the response regulator, usually leading to transcriptional activation of genes. TCS are widespread among bacteria, and the number of TCS encoding genes found in a bacterium is usually proportional to the size of its genome $[12,13]$.

Genome sequencing of B. cereus strain ATCC 14579 has revealed the presence of 55 sensor kinases $[14,15]$. Most of them are also found in other members of the B. cereus group for which the genome sequence is available, including $B$. anthracis and B. thuringiensis [16].

TCS controlling expression of virulence factors have been shown in several bacteria, including B. cereus. Recently, the B. cereus ResDE TCS which is involved in low oxydoreduction potential adaptation was shown to control enterotoxin production under anaerobiosis [17]. In contrast, the B. cereus YvrGH TCS, of which the encoding genes are located in the vicinity of the cytotoxin K encoding gene, was not required for expression of this virulence factor [18].

TCS encoding genes are often located in the same chromosomal region as the genes that they control, as for example in B. subtilis with the DesKR, CitST, YycFG, BceRS and LiaRS TCS [19-23]. In the B. cereus group, the TCS encoding $y v f T U$ genes are located in the vicinity of $p l c R$. To determine whether the YvfTU TCS plays a role in the expression of $p l c R$ and consequently of the PlcR regulon, the phenotype of a $y v f T U$ mutant constructed in the B. cereus strain ATCC 14579 was analyzed.

\section{Results \\ Identification of genes encoding a TCS in the vicinity of the plcR locus among the $B$. cereus group}

Genes encoding a TCS (BC5352 and BC5353) were located between $5,263 \mathrm{~kb}$ and $5,265 \mathrm{~kb}$ on the minus strand of the B. cereus ATCC 14579 chromosome (Fig. 1A). Using BlastP, the deduced amino acid sequences of BC5353 and BC5352 genes appeared to be homologous to both the B. subtilis YocF and YocG (now called DesK and DesR) (37 and 62\% identity, with E-values of 2e-60 and 2e-42, respectively) and the B. subtilis YvfT and YvfU (43 and $62 \%$ identity, with E-values of $9 e-78$ and $4 e-43$, respectively). In $B$. cereus ATCC 14579 , genes encoding a putative $\mathrm{ABC}$ transporter (BC5355 and $\mathrm{BC} 5354$ ) were located upstream from the $\mathrm{BC} 5353$ and $\mathrm{BC} 5352$ genes (Fig. 1A). Orthologous $\mathrm{ABC}$ transporter encoding genes were also located upstream from the yvfTU genes in $B$. subtilis (not shown). The BC5353 and BC5352 genes studied here have been annotated as yocF and yocG in the B. cereus strain ATCC 14579 [15]. However, these genes were previously annotated $y v f T$ and $y v f U$ in ATCC 14579 [5]. Because of (i) their higher sequence homologies with the $B$. subtilis $\gamma v f T$ and $y v f U$ genes, (ii) their conserved synteny with the B. subtilis yvfTU locus (including ABC transporter encoding genes), and (iii) their previous annotations, the BC5353 and BC5352 genes were named as $y v f T$ and $y v f U$, respectively, throughout the present work.

In the strain ATCC 14579, the yvfTU genes were located in the vicinity of plcR (BC5350) encoding a transcriptional regulator and its activating peptide encoding gene $p a p R$ (BC5349) (Fig. 1A). A putative protease encoding gene, $n p r B$ (BC5351), was found between $y v f U$ and plcR. Among the $B$. cereus group strains, the yvfTU genes were always located in the vicinity of plcR-papR (Fig. 1B). The synteny was conserved, except for $n p r B$ which is lacking in some strains of the $B$. cereus group. The presence or absence of the $n p r B$ gene seemed to be correlated to the taxonomic position of the strains $[24,25]$, according to the genome sequences available up to now in each taxonomic group.

\section{Domains in YvfT and YvfU}

Putative motifs present in the deduced amino-acid sequences of $y v f T$ and $y v f U$ were predicted according to the Smart tool: YvfT displays an ATP binding domain (HATPase domain), and a dimerisation and phosphoacceptor domain (PFAM:HisKA_3 domain). YvfT is most probably a membrane protein as revealed by the 4 predicted transmembrane domains in its $\mathrm{N}$-terminal region. This histidine kinase belongs to the class IIa defined by Fabret $e t$ al. [26], or to the class 7 according to Grebe and Stock [27]. YvfU, the cognate response regulator of YvfT belongs to the NarL class of response regulators [27]. YvfU displays a phosphoacceptor site (REC domain) in the N-terminal region. The DNA-binding motif (HTH domain) found in 




(B)

$\begin{array}{lccccccc} & \text { BC5355 } & \text { BC5354 } & \text { yvfT } & \text { yvfU } & \text { nprB } & \text { plcR } & \text { papR } \\ \text { Group III } & + & + & + & + & - & & ++^{\mathrm{a}} \\ \text { Group IV } & + & + & + & + & + & + \\ \text { Group VI } & + & + & + & + & + & + \\ \text { Group VII } & + & + & + & + & & + & + \\ & & + & + & + & +\end{array}$

\section{Figure I}

The B. cereus yvfTU chromosomal region. (A) Map of the B. cereus ATCC I4579 yvfTU chromosomal region. Grey arrows represent ORFs. The position of the kanamycin resistance gene integrated in the chromosome of the mutant to disrupt yvfTU is indicated. Small arrows represent promoters or putative promoters. Function or putative function of gene products: $B C 5355, A B C$ transporter ATP-binding protein; BC5354, ABC transporter permease protein; yvfT, two-component sensor kinase; yvfU, two-component response regulator; $n p r B$, metalloprotease; plcR, transcriptional activator; $p a p R$, PlcR activating peptide; Black box: PIcR recognition site. Lines annotated by numbers in brackets correspond to RT-PCR amplicons (see text and Fig. 2). In the yvfT promoter region, putative - 10 and -35 sigma $A$ boxes (underlined), initiation of transcription (bold underlined) and RBS (bold italic) are indicated In the yvfU 3'-region, one cytosine (bold underlined) which leads to a stop codon (italic underlined) was indicated in the ATCC 14579 genome sequence, but was lacking in our sequence data which gives a different stop codon (bold). The predicted stem-loop at the end of yvfU is represented. (B) Synteny of the yvfTU chromosomal region among the $B$. cereus group. Taxonomic group determined as previously described [24]. Studied strains were: Group III, B. cereus ATCC 10987; B. cereus ZK (E33L); B. thuringiensis konkukian; B. anthracis Sterne; B. anthracis Ames; $B$. anthracis Ames 058I; B. anthracis Ames ancestor; B. cereus W, B. thuringiensis Al Hakam. Group IV, B. cereus ATCC I4579; B. thuringiensis israelensis ATCC 35646. Group VI, B. weihenstephanensis KBAB4. Group VII, B. cereus NVH 39I/98, B. cereus NVH 883/00. a: truncated in B. anthracis strains.

the C-terminal region suggests a transcriptional regulator function. The YvfU TCS corresponds to the reference code 56 defined by de Been et al. [16].

According to the published genome sequence [15], the YvfU response regulator is smaller in strain ATCC 14579 than in other strains of the B. cereus group (not shown). However, our sequences from 3 independent PCR-amplified $y v f U$ fragments differed from the genome data, by the absence of a cytosine at the position 420 in the yvfU gene which created a frameshift. The yvfU gene was conse- quently 55 bp longer (Fig. 1A), and the C-terminal-end of YvfU (which contains the HTH domain) included therefore 18 additional amino-acids. Thus, YvfU from the ATCC 14579 strain displays a higher similarity with the other B. cereus group members' YvfU protein (Additional file 1).

\section{Construction of a yvfTU mutant}

A mutant was constructed in B. cereus ATCC 14579 by interrupting both the $y v f T$ and $y v f U$ genes. No difference was observed between $\Delta y v f T U$ and its parental strain dur- 


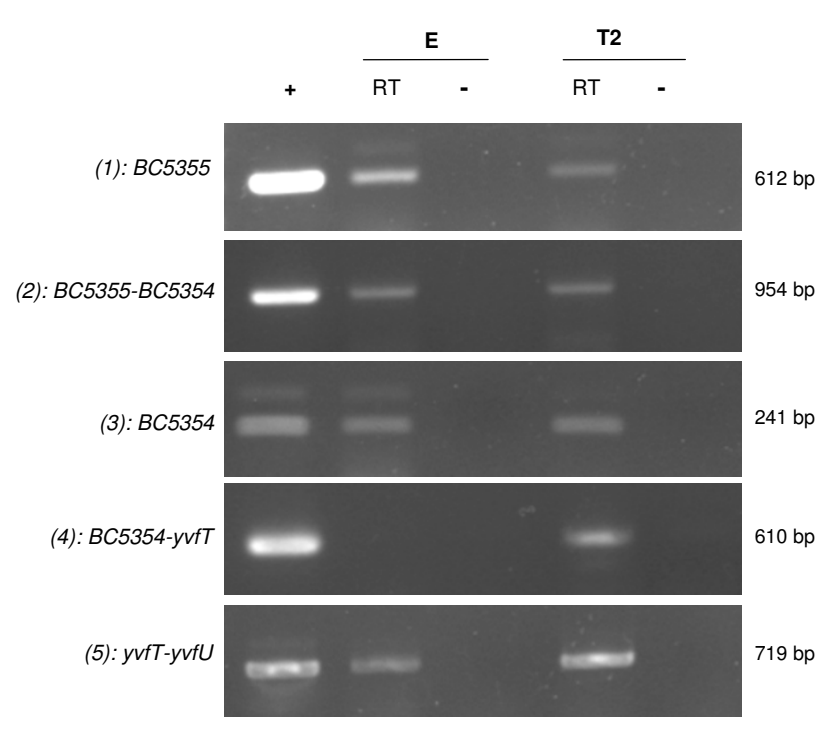

Figure 2

RT-PCR detection of yvfTU, BC5354 and BC5355 in B. cereus strain ATCC I4579. Lane "+": Positive control (PCR on genomic DNA). Lanes "RT": RT-PCR on 500 ng RNA. Lanes "-": Negative control (RT-PCR on 500 ng RNA with a heat-inactivated reverse-transcriptase). Numbers in brackets refer to the positions of the RT-PCR products on the yvfTU locus, as represented on Fig. IA. RNA extraction was performed on strains grown at $37^{\circ} \mathrm{C}$ in LB broth and harvested in exponential phase $(E)\left(O D_{600} \mathrm{I}\right)$, or 2 hours after the onset of stationary phase (T2).

ing growth in $\mathrm{LB}$ at various incubation temperatures $\left(15^{\circ} \mathrm{C}, 37^{\circ} \mathrm{C}\right.$ and $42^{\circ} \mathrm{C}$ ) (data not shown).

\section{Expression of genes mapping in the yvfTU locus}

RT-PCR was performed on RNA extracted from ATCC 14579 cells grown either in exponential $\left(\mathrm{OD}_{600}=1.0\right)$ or stationary phase at T2 (2 hours after the onset of stationary phase). The $\gamma v f T$ and $\gamma v f U$ genes were co-transcribed as indicated by the detection of mRNA overlapping both genes, during both exponential and stationary phase (panel 5 in Fig. 2). The genes encoding putative $\mathrm{ABC}$ transporters (BC5354 and BC5355, located just upstream from $y v f T U$ ) were also co-transcribed in the same growth conditions (panel 2 in Fig. 2). However, a signal overlapping BC5354 and $y v f T$ genes was detected by RT-PCR only on RNA extracted from cells harvested at T2 (panel 4 in Fig. 2). Thus, at certain growth stages, these 4 genes could be co-transcribed as a single operon.

The co-transcription of the $y v f T U$ genes alone (i.e. without a co-transcription with BC5355-BC5354) during exponential phase of growth suggested the existence of a specific promoter upstream from $y v f T$. This result was confirmed by the identification of the 5'-end of the yvfTU transcript mapping 25 bp upstream from the start codon
(Fig. 1A), using the rapid amplification of cDNA ends (RACE)-PCR technique.

A $y v f T^{\prime \prime} l a c Z$ transcriptional fusion was therefore constructed on a plasmid and transferred in both $B$. cereus ATCC 14579 and $\Delta y v f T U$ strains. Measurement of $\beta$-galactosidase activity throughout the kinetics of growth revealed a very low expression in both strains during the exponential phase and until two hours after the onset of stationary phase (mean values about 10 Miller units, Fig. $3)$. Then, $\beta$-galactosidase activity increased in both strains. These results indicate that $y v f T U$ was transcribed from its own promoter at a basal level in exponential phase of growth and transcription was increased during the stationary phase. No significant difference between the yvfTdirected lacZ transcription in the 2 strains at any time of the growth culture was observed $(P>0.05$, Student's $t$ test).

Because RT-PCR experiments revealed a co-transcription of yvfTU with the two BC5355 and BC5354 genes at T2, quantification of the promoter activity of the BC5355BC5354- $y v f T-y v f U$ operon, was performed by constructing a BC5355'lacZ transcriptional fusion. Measurements of the $\beta$-galactosidase activity at T2 in the $B$. cereus ATCC 14579 and $\Delta y v f T U$ strains were (mean \pm sd) $28 \pm 4$ and 22 \pm 13 Miller Units, respectively, and were not significantly different $(P>0.05$, Student t-test $)$.

Thus, disruption of the chromosomal $y v f T U$ genes did not alter the transcription of the plasmidic yvfTU promoter, nor that of the plasmidic BC5355 promoter, revealing that, in the tested conditions, the yvfTU operon was not autoregulated.

\section{plcR expression in the yvfTU mutant}

A transcriptional fusion between the plcR-promoter region from B. cereus strain ATCC 14579 and the lacZ reporter gene was constructed (Table 1 ) in order to determine the levels of plcR transcription in both the WT and $\Delta y v f T U$ strains throughout the kinetics of growth (Fig. 4). Measurement of $\beta$-galactosidase activity revealed that during the exponential phase, the $p l c R$ expression level was constant, ranging from 20 to 30 Miller units in both strains (no significant difference between the two strains). In contrast, during the stationary phase, plcR expression increased in both strains, but this increase was faster in the WT strain than in $\Delta y v f T U$. Thus, during stationary phase, a higher plcR expression was detected in the WT strain as compared to that in $\Delta y v f T U(P<0.05)$.

\section{Expression of the PlcR regulon in the yvfTU mutant}

To study the expression of the PlcR regulon in $\Delta y v f T U$, in comparison with that of its parental strain, a transcriptomic approach was performed. Bacteria were grown in LB 


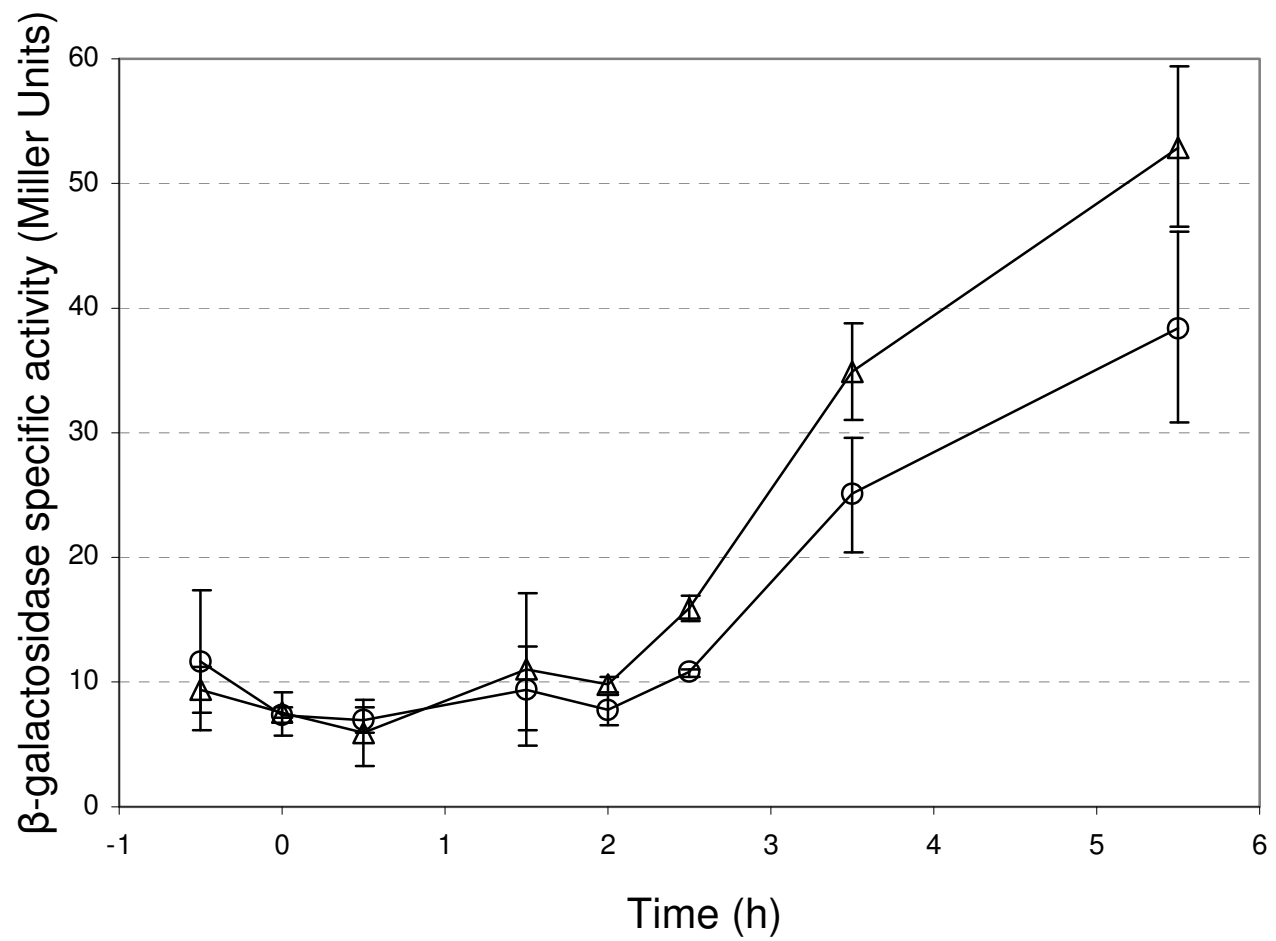

Figure 3

yvfT directed lacZ expression in B. cereus WT or yvfTU mutant strains. $\beta$-galactosidase activity was measured in either the WT strain (circles) or in the yvfTU mutant (triangles) harbouring pHT-yvfT'Z (649 bp yvfT promoter region cloned upstream from the promoterless lacZ reporter gene in pHT304-18Z). Time 0 indicates the onset of the stationary phase of growth. Each curve is the mean value of triplicate measurements, representative of 3 independent experiments. Bars represent standard deviation.

medium and were harvested two hours after the onset of the stationary phase of growth. At this time, $80 \%$ of the total amount of the extracellular proteins is produced in a PlcR-dependent manner [4].

The PlcR regulon has recently been thoroughly defined by a microarray-based approach [28]. Among the 45 genes belonging to this regulon, a significant differential expression of at least 1.5 fold was observed between the 2 strains for 11 of them by the transcriptome analysis (Table 2). These results revealed that the yvfTU mutation changed the expression of only a small part of the PlcR regulon at the transcriptional level, in the growth conditions used in this study.

Eight of these genes showed a reduced expression in $\Delta y v f T U$, including plcR and its activating peptide encoding gene $p a p R$. Relative real-time quantitative PCR (qRT-PCR) was performed and confirmed that in $\Delta y v f T U$, the plcR mRNA levels represented 0.48 fold (mean of 3 independent experiments, range 0.31-0.60) of the mRNA levels in the WT. Some genes such as $n p r B$, nheAB, plcB, encoding toxins or degradative enzymes, were also downregulated (Table 2). In contrast, the three genes encoding the haemolysin BL were overexpressed in the mutant. The $h b l C$ mRNA levels in qRT-PCR were 2.49 fold (range 2.392.60) higher in $\Delta y v f T U$ than in the WT and confirmed the results of the transciptomic analysis.

Complementation of the $\Delta y v f T U$ strain was performed by introducing the $y v f T U$ genes under the control of their own promoter on a plasmid (Table 1). The plcR mRNA level was quantified in the resulting strain harvested 2 hours after the onset of stationary phase. In the complemented $\Delta y v f T U$ strain, the mRNA level of $p l c R$ was restored: it was 1.4 fold higher than in the WT strain and 1.7 fold higher than in the WT strain harbouring the control plasmid (pHT304).

Because most virulence factors belonging to the PlcR regulon are extracellular proteins, the extracellular proteome from 4 cultures of each of WT and $\Delta y v f T U$ strains was also analyzed. Identification of proteins on gels after a twodimensional electrophoresis was based on previous spots 


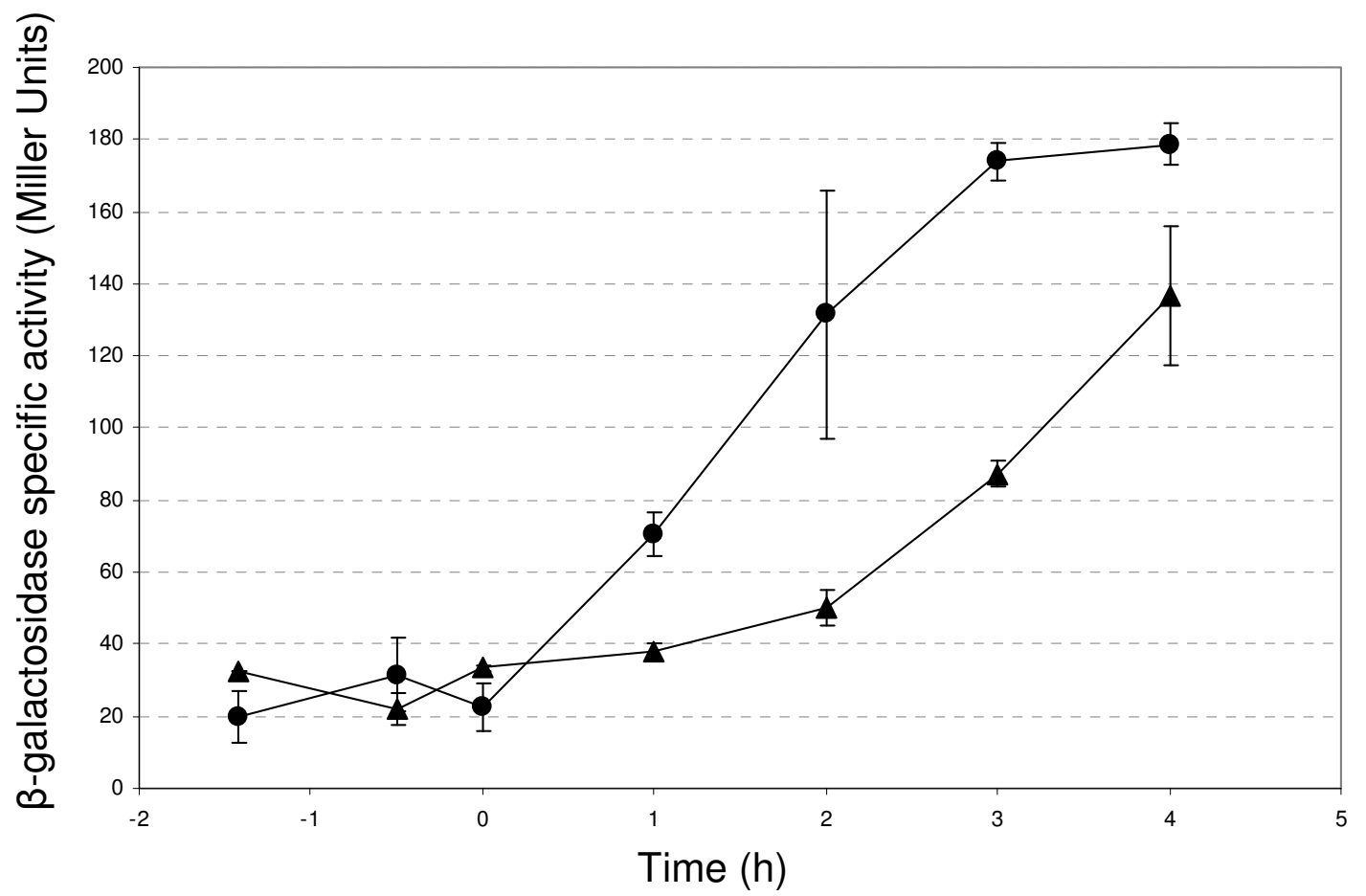

\section{Figure 4}

plcR directed lacZ expression in B. cereus WT or yvfTU mutant strains. $\beta$-galactosidase activity was measured in either the WT strain (circles) or in the yvfTU mutant (triangles) harbouring PHT-plcR'Z (plcR promoter region cloned upstream from the promoterless lac Z reporter gene in pHT304-I8Z). Time 0 indicates the onset of stationary phase. Each curve is the mean value of triplicate measurements, representative of 3 independent experiments. Bars represent standard deviation.

Table I: Strains and plasmids used in this study

\begin{tabular}{|c|c|c|}
\hline Strain or plasmid & Relevant genotype ${ }^{a}$ & Source or reference \\
\hline \multicolumn{3}{|l|}{ Strains } \\
\hline B. cereus ATCC 14579 & & Laboratory collection \\
\hline B. cereus $\Delta p l c R$ & ATCC I 4579 plcR::Km & [6] \\
\hline B. cereus $\triangle y v f T U$ & ATCC I 4579 yvfTU::Km & This work \\
\hline E. coli TGI & {$\left[\Delta\left(\right.\right.$ lac-proAB) supE thi hsd-5 (F' traD36 proA $A^{+}$proB ${ }^{+}$lacla lacZ $\left.\left.\Delta M \mid 5\right)\right]$} & Laboratory collection \\
\hline E. coli ETI 2567 & (F- dam-I3::Tn9 dcm-6 hsdM hsdR recFl 43 zjj-202: :Tn 10 galK2 galT22 aral 4 pacYI xyl-5 leuB6 thi-l) & Laboratory collection \\
\hline \multicolumn{3}{|l|}{ Plasmids } \\
\hline pUCI8 & $A p^{R}$ cloning vector & Laboratory collection \\
\hline PMAD & $A p^{R}$ and $E m^{R}$ shuttle vector & [45] \\
\hline $\mathrm{pHT} 304$ & $A p^{R}$ and $E^{R}$ cloning vector & [58] \\
\hline $\mathrm{pHT} 304-\mathrm{Km}$ & aphAlll with its own promoter cloned in Sall and Pstl sites of pHT304 & This work \\
\hline PMAD $\triangle$ yvfTU & Recombinant PMAD harboring yvfTU::Km & This work \\
\hline pHT304-I8'Z & $A p^{R}$ and $\mathrm{Em}^{\mathrm{R}}$ cloning vehicle; lac $Z$ reporter gene & [48] \\
\hline PHT-yvfTU & yvfTU and its promoter (25I4 bp) cloned in Pstl and EcoRI sites of pHT304 & This work \\
\hline pHT-plcR'Z & $\begin{array}{l}\text { I } 836 \text { bp region upstream from plcR start codon cloned between the Hindlll and Xbal sites of } \\
\text { pHT304- I8'Z }\end{array}$ & This work \\
\hline pHT-yvfT'Z & 649 bp region upstream from yvfT start codon cloned in Pstl and BamHI sites of pHT304-I8'Z & This work \\
\hline
\end{tabular}

a Km, kanamycin; Ap, ampicillin; Em, erythromycin 
Table 2: PIcR-regulon members differentially expressed in the yvfTU mutant

\begin{tabular}{|c|c|c|c|c|c|}
\hline NCBI ID & Putative gene product & yvfTU/WT'b & M-value & $P$-valued & Putative localisation \\
\hline BC0670 & phosphatidylcholine-preferring phospholipase C (PC-PLC) & 0.32 & -1.649 & 0.004 & Extracellular \\
\hline BC067|a & sphingomyelinase $\mathrm{C}$ & 0.33 & -1.582 & 0.006 & Extracellular \\
\hline $\mathrm{BC} 1809$ & enterotoxin (NheA) & 0.53 & -0.913 & 0.006 & Extracellular \\
\hline $\mathrm{BC} 1810^{\mathrm{a}}$ & enterotoxin (NheB) & 0.59 & -0.757 & 0.034 & Extracellular \\
\hline $\mathrm{BC} 3102^{\mathrm{a}}$ & Hemolysin BL binding component precursor $(\mathrm{HblB})$ & 1.94 & 0.953 & 0.027 & Extracellular \\
\hline $\mathrm{BC} 3103^{\mathrm{a}}$ & Hemolysin BL lytic component LI (Hbl-LI) & 1.92 & 0.944 & 0.022 & Extracellular \\
\hline BC3 104 & Hemolysin BL lytic component L2 (Hbl-L2) & 2.21 & 1.147 & 0.002 & Extracellular \\
\hline BC5I0I & thiol-activated cytolysin (Cereolysin O) & 0.66 & -0.610 & 0.029 & Extracellular \\
\hline BC5349 & PapR protein & 0.59 & -0.773 & 0.033 & Extracellular \\
\hline BC5350 & PlcR Transcriptional activator & 0.52 & -0.933 & 0.001 & Cytoplasmic \\
\hline BC535I & Bacillolysin (NprB) & 0.34 & -1.560 & 0.001 & Extracellular \\
\hline
\end{tabular}

a Genes without a PlcR box found directly upstream, but located in a putative PlcR-regulated operon.

b Absolute ratio of expression in the yvfTU mutant vs WT. Up- or downregulation of more than I.5 fold are presented.

c $\log _{2}$ of the absolute ratio. Negative M-value, downregulated in the mutant; positive M-value, upregulated in the mutant. M-values of more than

0.59 or less than -0.59 (corresponding to an 1.5 fold up- or downregulation in the mutant, respectively) are presented.

$d P$-value $<0.05$ obtained with the t-test was considered as significant

annotations performed in similar experimental conditions [29]. For confirmation, 8 spots were analysed by Mass-Spectrometry.

Using the software ImageMaster Platinum, spot volume quantification was performed after normalization and a Kruskal-Wallis (KW) test was applied to detect reproducible differences between the extracellular proteomes of the two strains. Some differences were observed for spots corresponding to NprB and PC-PLC (Fig. 5). The three spots corresponding to three isoforms of NprB were found in a significant higher amount in the extracellular proteome of the WT (mean 7.09\% vol, range 5.28-9.57) when compared to that of the yvfTU mutant (mean $3.31 \%$ vol, range 1.54-5.45) (differences in the KW test significant at $P=$ $0.02)$. Similarly, the mean \% vol of spots corresponding to PC-PLC (encoded by the plcB gene) represented 4.24 (range 3.22-6.16)\% vol and 1.26 (range $0.16-2.89$ )\% vol in the extracellular proteomes of the WT and $\Delta y v f T U$, respectively (difference significant in KW test at $P=0.05$ ).

The total amount of Nhe represented 8.21 (range 3.67$12.38) \%$ vol and 5.20 (range $2.08-8.00$ )\% vol (for NheA) and 6.14 (range 5.39-7.69) and 4.66 (range 3.59-7.24)\%
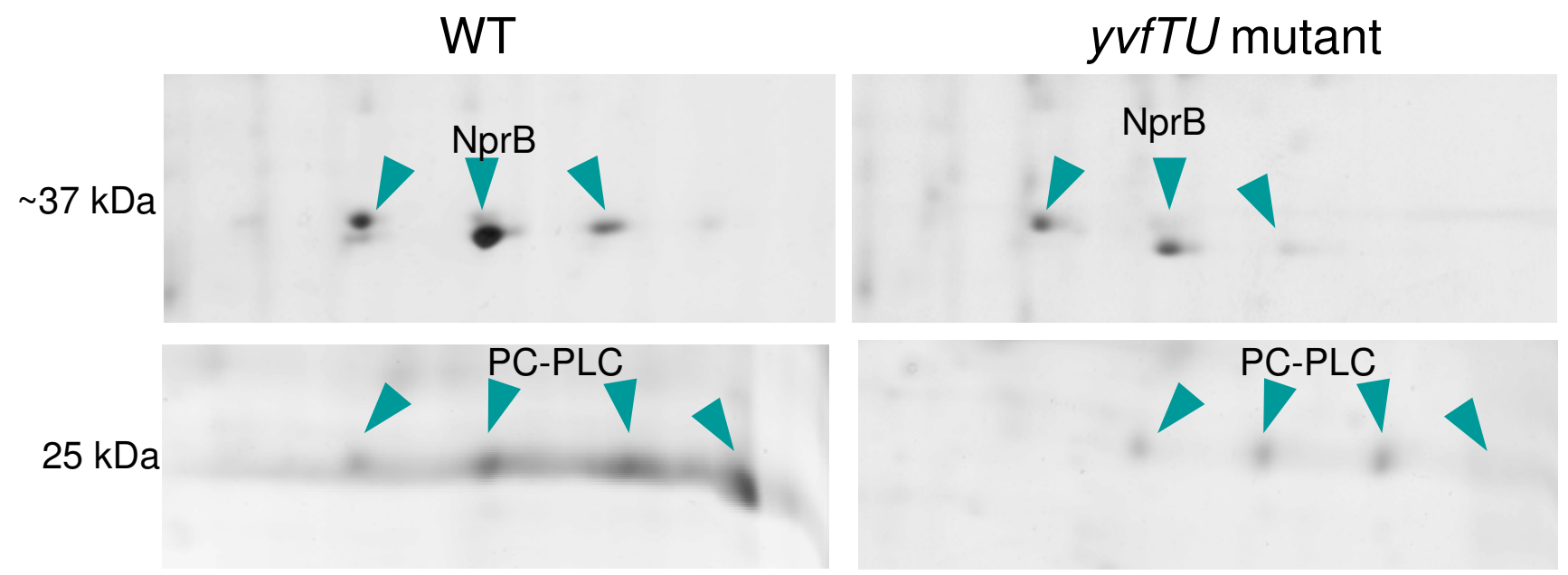

\section{Figure 5}

2D-GE of WT and yvfTU mutant culture supernatants collected 2 hours after the onset of stationary phase.

Spots found in lower amount in the extracellular proteome of the yvfTU mutant correspond to NprB and PC-PLC proteins, as confirmed by Mass Spectrometry identification. The different spots correspond to isoforms of the same protein, with distinct charges but identical molecular weights. The gel areas shown are located around $37 \mathrm{kDa}$ with a pl between 5.5 and 6 for NprB, and $25 \mathrm{kDa}$ with a pl between 6.0 and 7.0 for PC-PLC. 
vol (for NheB), in the WT and $\Delta y v f T U$ extracellular proteomes, respectively. Although differences were not significant ( $P>0.05$ in KW test), in each of the 4 runs, the amount of NheA and NheB was always higher in the gels of the WT extracellular proteome than in those of $\Delta y v f T U$ (differences significant at $P=0.03$ for NheB and at $P=$ 0.06 for NheA in a paired t-test).

Apart from those differences, the extracellular proteomes of both strains were similar. In particular, the amount of the other extracellular proteins known to be expressed in a PlcR-dependent manner was not significantly affected by the yvfTU mutation, confirming the small number of changes in expression of the PlcR regulon observed by the transcriptomic analysis.

\section{Role of YvfTU in some virulence features}

Virulence of the yvfTU mutant was estimated in a Galleria mellonella infection model. Injection of various doses (200 to 20,000 cfu) of WT and yvfTU mutant was performed into the G. mellonella hemocoel (blood of the insect).

By using a Probit analysis software, the $\mathrm{LD}_{50}$ at 24 hours post infection were estimated. For the wild type the $\mathrm{LD}_{50}$ was $2.5 \times 10^{3}\left(95 \%\right.$ confidence limits from $1.8 \times 10^{3}-3.6$ $\times 10^{3}$ ) CFU and for the $\Delta y v f T U$ mutant the $\mathrm{LD}_{50}$ was $4.2 \times$ $10^{3}\left(95 \%\right.$ confidence limits from $\left.3.2 \times 10^{3}-5.8 \times 10^{3}\right)$ CFU. Test of parallelism and the virulence ratios at the $\mathrm{LD}_{50}$ level showed a significant $\left(\left(P<0.05, \mathrm{X}^{2}\right.\right.$ test $)$ but small decrease (1.6 fold with (1.3-2.1, 95\% confidence limits)) in virulence with the $\Delta y v f T U$ mutant compared to the WT. No difference between $\Delta y v f T U$ and the WT in time-to-death was noticed (data not shown).

When grown on sheep blood agar, the $\Delta y v f T U$ and the WT strains displayed an identical hemolysis phenotype. The two strains did not show significant difference in cytotoxicity on HeLa cells and on macrophages (data not shown).

\section{Discussion}

Some orthologs of the B. cereus yvfTU genes are found in other Bacillus species. However, in none of these organisms the YvfTU function has been studied. Although the exact function of many TCS is unknown, the TCS encoding genes are often located in the same chromosomal region as the genes that they control. Among the B. cereus group members, the yvfTU genes are highly conserved, and are always located in the vicinity of plcR. Because of this conserved synteny, we hypothesized a link between YvfTU and PlcR. Expression of $p l c R$ was therefore studied in a yvfTU mutant. The lower $\beta$-galactosidase activity measured in $\triangle y v f T U$ harboring a plcR'lacZ transcriptional fusion revealed a transcription of $p l c R$ partly depending on YvfTU. This dependence between YvfTU and plcR expression was confirmed by transcriptome analysis and quantitative real-time PCR.

Because the expression of plcR was affected by the yvfTU mutation, we wondered about a consequently modified expression of the PlcR regulon. The transcriptome and the extracellular proteome of both the WT and $\Delta y v f T U$ strains were analyzed, at the time of maximum protein concentration in the culture supernatant [30] and when $80 \%$ of the total amount of the produced proteins is expressed in a PlcR-dependent manner [4] (i.e. two hours after the onset of the stationary phase). At this stage, $y v f T U$ genes were transcribed, and the plcR transcription was partly YvfTU-dependent. Despite a lower level of plcR mRNA in $\Delta y v f T U$, the transcriptomic and proteomic analysis both revealed that the expression of the PlcR regulon was mostly not affected by the yvfTU mutation. This suggests that PlcR can play its regulatory role even when expressed at a low level.

However, our results revealed that the decrease in plcR mRNA levels caused by the yvfTU mutation was concomitant to a differential expression at the transcriptional level of 11 PlcR-regulated genes, with 8 genes showing a reduced expression in $\Delta y v f T U$. An increase in expression of the 3 genes belonging to the $h b l$ operon was observed in $\Delta y v f T U$ where plcR is expressed at a lower level, while $h b l$ is known to be expressed in a PlcR-dependent manner $[3,4]$. Although performed in different growth conditions, such a lack of congruence between the trends of transcription of several PlcR-regulated genes (including $h b l$ ) and expression of plcR itself has been previously shown [31]. Furthermore, the recent discovery of the involvement of another regulator (Fnr) in $h b l$ expression emphasizes the fine regulations occurring in $B$. cereus in addition to the PlcR regulation $[32,33]$. The differential response of several genes among a particular regulon has been observed many times elsewhere, and it was recently suggested that in $B$. cereus, some diversity in the regulation of gene expression occurs within the PlcR regulon [30]. All these findings, coupled with our results, suggest that expression of $h b l$ and some other members of the PlcR regulon can undergo subtle regulations which also involve yet unidentified factors, different from PlcR.

For several genes showing reduced expression at the transcriptional level in $\Delta y v f T U$, a concomitant decrease in the amount of their products was detected by 2D gel analysis. In some cases, differential expression was only observed with the transcriptomic approach (for example, the Cereolysin $\mathrm{O}$ encoding gene). The relatively low levels of differential expression observed with the transcriptome analysis suggest that the proteomic approach was less sensitive in our conditions. Furthermore, various post-transcriptional regulations might explain the lack of 
correlation between transcriptomic and proteomic approaches, as reported in several studies on other organisms (for example, see references [34-37]).

In bacterial pathogens, several TCS mutants present attenuation in virulence [38]. In our study, the virulence of $\Delta y v f T U$ in the G. mellonella insect was also slightly lower than that of the WT strain. The reduced expression of $n$ prB, $p l c B$ and $n h e A B$ coupled with the lower amount of their products found in the extracellular proteome of $\Delta y v f T U$ may account for this reduction in virulence. However, this only slightly impaired virulence is not surprising, as $\Delta y v f T U$ did not present a major alteration of the PlcR regulon, and considering the importance of this regulon in $B$. cereus insect virulence [6].

Expression of chromosomal genes not regulated by $p l c R$ was also affected by the yvfTU mutation, as observed with the transcriptomic analysis (additional file 2). Among them, 29 and 25 genes showed respectively higher and reduced expression by 2 fold or more. However, no major pathway was over-represented in this gene list, giving no clue for the identification of a signal triggering the activation of the YvfTU TCS. An alignment of 1,000 bp promoter regions of the genes listed in additional file 2 was performed using the MEME programme. However, no conserved sequence was identified, suggesting that no highly conserved regulatory motif was responsible for an YvfTU-dependent differential expression in these promoter regions.

\section{Conclusion}

This work showed that YvfTU and PlcR are genetically linked. A functional link was also shown by the identification of a YvfTU dependent plcR expression. The decreased plcR expression observed in $\Delta y v f T U$ only slightly modified the expression of the PlcR regulon, and slightly decreased the virulence of $B$. cereus in an insect model. A subtle regulation for some virulence factors produced by B. cereus exists in addition to the PlcR regulation.

\section{Methods}

Strains and growth conditions

All bacterial strains and plasmids used in this study are listed in Table 1. E. coli and B. cereus cells were routinely grown in Luria broth (LB) medium with vigorous agitation at $37^{\circ} \mathrm{C}$. When required, the antibiotic concentrations used for bacterial selection were: erythromycin at 10 $\mu \mathrm{g} \mathrm{ml}^{-1}$ or kanamycin at $150 \mu \mathrm{g} \mathrm{ml}^{-1}$ for B. cereus and ampicillin at $100 \mu \mathrm{g} \mathrm{ml}^{-1}$ for E. coli. Bacteria with the $\mathrm{Lac}^{+}$phenotype were identified on LB agar containing $40 \mu \mathrm{g} \mathrm{ml}^{-1} \mathrm{X}$ Gal. Columbia agar plates containing 5\% sheep blood (BioMérieux) were used to assay the hemolytic activity of the strains.

\section{In silico analysis}

tblastn alignments were performed on NCBI web site: http://www.ncbi.nlm.nih.gov/BLAST/[39]. Protein domains in YvfT and YvfU were identified using SMART software [40,41]. MEME programme was used to perform alignments of promoters of upregulated and downregulated genes in the yvfTU mutant [42].

\section{DNA manipulation}

Plasmid DNA was extracted from E. coli and B. cereus by a standard alkaline lysis procedure using the Wizard SV miniprep purification system (Promega), with the following modification in the first step of the lysis procedure for B. cereus: incubation at $37^{\circ} \mathrm{C}$ for $1 \mathrm{~h}$ with $5 \mathrm{mg}$ of lyzosyme $\left(14,300 \mathrm{U} \mathrm{mg}^{-1}\right)$. Chromosomal DNA was extracted from B. cereus cells harvested in mid-log phase as described previously [43]. Restriction enzymes and T4 DNA ligase were used as recommended by the manufacturer (Promega). Oligonucleotide primers were synthesized by Eurogentec. PCR was performed in a GeneAmp PCR system 2400 thermal cycler (Perkin-Elmer), using the Expand high fidelity DNA polymerase (Roche). Amplified DNA fragments were purified by using the PCR purification Kit (Roche) and separated on $0.7 \%$ agarose gels after digestion. Digested DNA fragments were extracted from agarose gels with a centrifugal filter device (montage DNA gel extraction kit; Millipore). All constructions were confirmed by DNA sequencing (GenomeExpress, Grenoble, France). Electroporation to transform B. cereus was used as previously described [44].

\section{RT-PCR and characterization of the yvfT-yvfU transcriptional unit}

Total RNA was extracted from B. cereus ATCC 14579 wildtype (WT) cells grown aerobically in LB medium at the end of exponential phase $\left(\mathrm{OD}_{600}=1.0\right)$, or two hours after the onset of stationary phase (T2), using the RNA extraction Pro-blue kit as recommended by the manufacturer (Q-Biogen). cDNA synthesis from $1 \mu \mathrm{g}$ of total RNA was performed by using AMV-RT polymerase according to the instructions given by the RT-PCR kit (Roche). Specific amplifications were performed with the primers 5355-F and 5355-R (Table 3) for the BC5355 gene, 5355-F and 5355-54-R for a region overlapping BC5355 and BC5354, PyvfT-F and 5354-R for the BC5354 gene, 5Up-KR and yvfT-54-R for a region overlapping BC5354 and $\gamma v f T$, and yvfTU-F and yvfTU-R for a region overlapping $\gamma v f T$ and $y v f U$. This step was coupled with 30 cycles of PCR amplification with Expand-HighFidelity polymerase as recommended (Roche). The yvfTU transcription start site was determined by the RACE-PCR kit (Roche) using yvfT-R2 and yvfT-R3 oligonucleotides (Table 3), following the manufacturer's instructions. 
Table 3: Primers used in this study

\begin{tabular}{|c|c|c|}
\hline Primer name & 5'-3' sequence ${ }^{a}$ & Restriction sites \\
\hline $5 U p-K R$ & GCTACCATGGCTTCTAAAAATTACACCGCTTC & Ncol \\
\hline $3 U_{p-K R}$ & GCTAGTCGACCATTAAAATAAACATTGGAACG & Sall \\
\hline 5Dn-KR & GCTACTGCAGAGATTTAATGTTTGGCTTATGG & Pstl \\
\hline 3Dn-KR & GGTAGGATCCTACACGGTTTTGATTCTACTGA & $\mathrm{BamHI}$ \\
\hline Km5in & 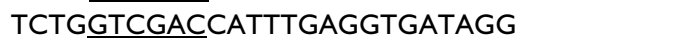 & Sall \\
\hline Km3in & GCTACTGCAGATCGATACAAATTCCTCGTAGGCG & Pstl \\
\hline Km5out & CGGTATAATCTTACCTATCACC & \\
\hline Km3out & TACTCTGATGTTTTATATCTTTTCTAA & \\
\hline PyvfT-F & CGCCTGCAGTTATTAATGCCTGTTATGTTTT & Pstl \\
\hline PyvfT-R & CGCGGATCCTGTCTTTTTCTTATATATATTG & $\mathrm{BamHI}$ \\
\hline CP-yvfTU & CGTCGAATTCATTTGAAGCACACGGTTAC & EcoRI \\
\hline PplcR-R & GGCGTCTAGACCCATTAGAACAATCTAATTTT & Xbal \\
\hline PplcR-F & GACGAAGCTTATTCATTTGATACGGCAGTG & HindllI \\
\hline $5355-\mathrm{F}$ & GATAGTATTACGGTGGAAGAGG & \\
\hline $5355-R$ & AAACTGTTCAAATGCTTCAT & \\
\hline $5355-54-R$ & CTGTTTGAGCGATAATTTTT & \\
\hline $5354-R$ & CTGTTTGAGCGATAATTTTT & \\
\hline yvfT-54-R & СTATTACAAGCTTCCATCCTGATGCC & \\
\hline yvfTU-F & TTGTGAAAAATCCAGAGCGTGC & \\
\hline yvfTU-R & ATCCAATCCACTTTGAATCGGC & \\
\hline yvfT-R2 & CTATTACAAGCTTCCATCCTGATGCC & \\
\hline yvfT-R3 & CGCAAGCTTCAAACCACATATACGGGAAG & \\
\hline LC-I6S-F & GGTAGTCCACGCCGTAAACG & \\
\hline LC-I6S-R & GACAACCATGCACCACCTG & \\
\hline LC-plcR-F & TCCAGCAATTTCTTCAATGG & \\
\hline LC-plcR-R & TCGGCATGATATTTCAATCG & \\
\hline LC-hblC-F & TTCAAGCAGAAACTCAACAG & \\
\hline LC-hblC-R & TTCAAGTCTATCCGAAAACC & \\
\hline
\end{tabular}

a Restriction enzyme sites are underlined

\section{Mutant construction}

The two contiguous genes encoding the TCS YvfTU were interrupted by allelic exchange with a cassette conferring kanamycin resistance (KmR) in B. cereus ATCC 14579 as previously described [45]. Briefly, a fragment of $912 \mathrm{bp}$ corresponding to the upstream region of BC5353 ( $y v f T$ ) was PCR amplified using primers 5Up-KR and 3Up-KR (Table 3). Similarly, a 967 bp fragment corresponding to the downstream region of BC5352 ( $y v f U$ ) was PCR amplified using primers 5Dn-KR and 3Dn-KR (Table 3). PCR fragments were cloned in the pUC18 plasmid, in accordance with the endonuclease restriction sites previously introduced in the primers (Table 3 ). In parallel, the $1.5 \mathrm{~kb}$ fragment corresponding to the aphA3 kanamycin resistance gene with its own promoter was PCR amplified using primers Km5in and Km3in, and pDG783 as a DNA template $[46,47]$, and cloned in the pHT304 plasmid (Table $1)$. The DNA fragments corresponding to the upstream and downstream yvfTU region and the KmR cassette were digested with the appropriate enzymes, purified and cloned altogether in the NcoI and BamHI sites of the thermosensitive plasmid pMAD (Table 1). Ten $\mu \mathrm{g}$ of the recombinant plasmid pMAD $\Delta y v f T$ were used to transform B. cereus ATCC 14579, and subjected to allelic exchange as previously described [45]. Strains that were resistant to kanamycin and sensitive to erythromycin arose through a double cross-over event in which the chromosomal $y v f T U$ copy was replaced with the KmR cassette. The chromosomal allele exchange in the yvfTU mutants was checked by DNA sequencing of PCR fragments amplified using the primers couples Km5out/5UpKR and Km3out/3Dn-KR.

Complementation of the mutant was performed as follows: a PCR amplified fragment using primers PyvfT-F and Cp-yvfTU was cloned between the PstI and EcoRI sites of pHT304 and introduced in B. cereus $\Delta y v f T U$ by electroporation.

\section{Construction of lacZ transcriptional fusions and $\beta$ - Galactosidase assay}

The DNA fragment harbouring the promoter regions were PCR amplified and digested according to the endonuclease sites introduced in the primers (see Table 3). The lacZ transcriptional fusions were constructed by cloning these DNA fragments between the corresponding sites of the low copy plasmid pHT304-18'Z [48]. The recombinant plasmids were introduced into B. cereus ATCC 14579 WT 
and $\Delta y v f T U$ strains by electroporation. B. cereus strains harbouring plasmids with lacZ transcriptional fusions were cultivated in $\mathrm{LB}$ medium at $37^{\circ} \mathrm{C}$. $\beta$-Galactosidase specific activities were measured in triplicate samples from each culture as previously described [43] and were expressed in units of $\beta$-galactosidase per milligram of protein (Miller units). Total proteins in the sample were quantified using the Bradford method (BioRad protein assay). Experiments were repeated three times. Error bars indicate standard deviations of triplicate measurements.

\section{Transcriptome analysis}

Three independent cultures of B. cereus ATCC 14579 WT and $\Delta y v f T U$ strains were cultured in LB medium at $30^{\circ} \mathrm{C}$ with shaking and harvested 2 hours after the onset of the stationary phase of growth (T2), as described previously [4].

Total RNA was extracted with the protocol described previously [31] modified as follows: frozen cell pellets from $10 \mathrm{ml}$ culture were supplemented with $1 \mathrm{ml}$ of TES buffer (0.03 M Tris pH 8.0, 0.005 M EDTA, $0.05 \mathrm{M} \mathrm{NaCl}$ ). Disruption of the cells was performed by adding $0.3 \mathrm{~g}$ sterile glass-beads (Sigma) followed by a $40 \mathrm{sec}$. run on a FastPrep Instrument (MP Biomedical). For each slide, cDNA was generated as described previously on $20 \mu \mathrm{g}$ of isolated RNA from the wild-type strain and $20 \mu \mathrm{g}$ of RNA from the mutant strain [31]. After purification, the cDNA's were labeled with Cy3 (wild-type) and Cy5 (mutant) and vice versa for the dye-swapped slides. The combined cDNA's of wild-type and mutant were hybridized onto a micro-array of 70-mer oligonucleotides, which represent all 5,255 open reading frames of the $B$. cereus ATCC 14579 genome (design: see [31]). As described previously [31], the slides were incubated overnight at $42^{\circ} \mathrm{C}$ and, after washing, scanned with an Axon 4000B scanner (Molecular Devices Corp., California). Further processing of the scanned slide and the subsequent data analysis was performed as described [31], using GenePix Pro, version 6.0 software (Molecular Devices Corp.).

\section{Relative quantification of gene expression by real-time PCR}

Real-time RT-PCR was performed on a Light-Cycler instrument (Roche) as previously described [17]. Briefly, the LightCycler RNA Amplification kit SYBR Green I (Roche) was used according to the manufacturer's instructions, with the following modifications: $5 \mathrm{ng}$ of total RNA were used as a template; the reverse transcription step was performed at $50^{\circ} \mathrm{C}$, and the annealing temperature during the 45 cycles of amplification was $50^{\circ} \mathrm{C}$. Oligonucleotides listed in Table 3 with a name beginning with "LC" were used for Real-time PCR. PCR amplification were performed on 500 ng of each RNA sample, in order to check for absence of contaminating DNA. The mRNA level changes for each gene were normalized to the RNA level of the ssu gene encoding 16S RNA and quantified as previously described [49].

\section{Extracellular proteome analysis}

Independent cultures of WT $(\mathrm{n}=4)$ and $\Delta y v f T(\mathrm{n}=4)$ were performed as indicated above for transcriptome analysis. As previously described [4], the supernatant of harvested cultures was filter-sterilized and proteins were precipitated with deoxycholate-tetrachloroacetic acid method. After ethanol:ether (vol/vol) washing, the protein pellet was stored at $-80^{\circ} \mathrm{C}$ until use. Quantification of the protein content in the samples was performed by the Bradford method. For both strains, $100 \mu \mathrm{g}$ of total proteins were loaded on an immobilized $\mathrm{pH}$ gradient strip (pH 4 to 7, $17 \mathrm{~cm}$ length, BioRad). After the isoelectrofocalisation, the strips were loaded on $12 \%$ polyacrylamide gels before the second dimension was run. Gels were silver stained [50], scanned, and analyzed with the ImageMaster platinum software (Amersham Biosciences) using the total spot volume normalization procedure. Four electrophoresis runs were performed with two gels, one of each WT and one of each $\Delta y v f T U$ supernatants. Finally, 8 gels were analyzed.

Statistical analysis of relative spot quantification was performed as follows: comparison of spot relative volumes in 4 replicate cultures of the extracellular proteomes of both strains was carried out using Kruskall Wallis non parametric test. A paired t-test was used to detect differences in spots volumes between strains in each of the 4 different runs (Systat version 9; SPSS; Chicago, IL, USA).

When necessary, a Coomassie-Blue staining $[51,52]$ was performed on gels loaded with $500 \mu \mathrm{g}$ of proteins, and spots were excised from the gels and digested with 0.1 to $0.5 \mu \mathrm{g}$ of trypsin (Promega) at $37^{\circ} \mathrm{C}$ during $6 \mathrm{~h}$. The digested proteins were analysed by MALDI-TOF MS on the PAPSS (Plateau d'Analyse Protéomique par Séquençage et Spectrométrie de Masse) at INRA Jouy-en-Josas, France. Peptide mass fingerprints were analyzed with ProteinProspector and Mascott softwares using the B. cereus ATCC 14579 genome database [53].

\section{Cytotoxicity of the yvfTU mutant}

Cytotoxicity assay was performed on HeLa cells and murine macrophages as described previously $[43,54]$.

\section{Insects and infection experiments}

The virulence-related properties of $y v f T U$ were assessed by comparing the killing effect of the B. cereus WT and $\Delta y v f T U$ strains by infection in $5^{\text {th }}$ instar (last larval stage before pupation) Galleria mellonella larvae. G. melonella eggs were hatched at $25^{\circ} \mathrm{C}$ and the larvae reared on beeswax and pollen (Naturalim). Groups of 20 G. mellon- 
ella larvae, each weighing about $200 \mathrm{mg}$, were used. Direct injection into the hemocoel was performed with various doses (ranging from 200 to 20,000 cfu) of vegetative bacteria, collected during exponential growth $\left(\mathrm{OD}_{600}=1\right)$. Tests were run 5 times with $4-5$ different doses per test.

Infected larvae were kept at $37^{\circ} \mathrm{C}$ and mortality was recorded at $24 \mathrm{H}$ and $48 \mathrm{~h}$. The $50 \%$ lethal doses $\left(\mathrm{LD}_{50 \mathrm{~s}}\right)$ values were estimated by Probit analysis at $24 \mathrm{H}$ post infection [55,56]. The Probit program (Praxeme, France) tests for the linearity of dose-mortality curves, provides lethal doses and the slope of each dose-mortality line. It tests the parallelism of 2 or more dose-mortality lines and determines the virulence ratio between the bacterial strains. Using the $\mathrm{X}^{2}\left(\mathrm{Chi}^{2}\right)$ test, the ratio is considered to be significantly different $(P<0.05)$ when the confidence limits do not include the value 1 .

\section{Authors' contributions}

JB designed the study, performed the majority of the experiments, analysed the data, and wrote the manuscript. KS performed the transcriptome experiments, $\mathrm{CM}$ performed the proteome experiments, $\mathrm{CD}$ performed the phenotypic characterisation of the mutant, MG participated in the design of the proteome experiments, $\mathrm{CNL}$ analysed the data of the insect virulence experiments and contributed to writing, NR did cytotoxicity assays. ABK, CNT, DL and VB participated in the design of the study. VB participated in the analysis of the data. All authors read, critically revised, and approved the final manuscript.

\section{Additional material}

\section{Additional File 1}

Alignments between the C-terminal ends of YvfU from members of the B. cereus group. Alignments were performed with the MultAlin version 5.4.1 program [57]. The YvfU sequences were deduced from the genome sequences available in the databases. Diverging amino acids are shown in grey boxes. The HTH domain is double underlined. $\mathrm{Ba}$ : $\mathrm{B}$. anthracis. The YvfU sequence of strains Ames Ancestor, Ames and Sterne is similar and is indicated only once. Btkonk: B. thuringiensis serovar konkukian str. 97-27; BtAlHakam: B. thuringiensis str. Al Hakam; Bc10987: B. cereus ATCC10987; BcZK: B. cereus EL33; BcG9241: B. cereus G9241; BwKBAB4: B. weihenstephanensis KBAB4; Bc39198: B. cereus subsp cytotoxicus strain NVH 391-98; Bc14579: B. cereus ATCC 14579 (genome data); Bc14579cor: B. cereus ATCC 14579 with the corrected yvfU sequence (according to our sequence data).

Click here for file

[http://www.biomedcentral.com/content/supplementary/14712180-8-183-S1.doc]

\section{Additional File 2}

Genes 2 fold differentially expressed in the B. cereus yvfTU mutant strain as identified by transcriptome analysis.

Click here for file

[http://www.biomedcentral.com/content/supplementary/14712180-8-183-S2.pdf]

\section{Acknowledgements}

Nathalie Gilois and Mireille Faurobert are greatly acknowledged for excellent advices in proteome experiments. We also acknowledge Céline Henry for the MS-analysis, Frédéric Carlin for many helpful discussion, Lucien Botella and Christophe Buisson for technical assistance, and A. Zigha, O. Ouhib and C. Duport for gift of some primers. This work was supported by INRA (Institut National de la Recherche Agronomique) and partly from a Grant ANR-05-PNRA-0 13. It was also supported by the Norwegian Research Council through a Strategic University Program and the Consortium for Advanced Microbial Sciences and Technologies (CAMST-FUGE).

\section{References}

I. Daffonchio D, Cherif A, Borin S: Homoduplex and heteroduplex polymorphisms of the amplified ribosomal 16S-23S internal transcribed spacers describe genetic relationships in the "Bacillus cereus group". Appl Environ Microbiol 2000, 66( I 2):5460-5468.

2. Helgason E, Økstad OA, Caugant DA, Johansen HA, Fouet A, Mock $M$, Hegna I, Kolstø $A B$ : Bacillus anthracis, Bacillus cereus, and Bacillus thuringiensis-one species on the basis of genetic evidence. Appl Environ Microbiol 2000, 66(6):2627-2630.

3. Agaisse $H$, Gominet $M, \varnothing$ kstad OA, Kolstø $A B$, Lereclus D: PIcR is a pleiotropic regulator of extracellular virulence factor gene expression in Bacillus thuringiensis. Mol Microbiol 1999, 32(5): $1043-1053$

4. Gohar M, Økstad OA, Gilois N, Sanchis V, Kolstø AB, Lereclus D: Two-dimensional electrophoresis analysis of the extracellular proteome of Bacillus cereus reveals the importance of the PIcR regulon. Proteomics 2002, 2(6):784-791.

5. Økstad OA, Gominet M, Purnelle B, Rose M, Lereclus D, Kolstø AB: Sequence analysis of three Bacillus cereus loci carrying PIcRregulated genes encoding degradative enzymes and enterotoxin. Microbiology 1999, I 45:3 |29-3। 38.

6. Salamitou S, Ramisse F, Brehelin M, Bourguet D, Gilois N, Gominet $M$, Hernandez $E$, Lereclus $D$ : The plcR regulon is involved in the opportunistic properties of Bacillus thuringiensis and Bacillus cereus in mice and insects. Microbiology 2000, 146:2825-2832.

7. Callegan MC, Kane ST, Cochran DC, Gilmore MS, Gominet M, Lereclus D: Relationship of plcR-regulated factors to Bacillus endophthalmitis virulence. Infect Immun 2003, 7 I (6):3 I I6-3I 24.

8. Lereclus D, Agaisse H, Gominet M, Salamitou S, Sanchis V: Identification of a Bacillus thuringiensis gene that positively regulates transcription of the phosphatidylinositol-specific phospholipase $C$ gene at the onset of the stationary phase. J Bacteriol 1996, I78(I0):2749-2756.

9. Gominet M, Slamti L, Gilois N, Rose M, Lereclus D: Oligopeptide permease is required for expression of the Bacillus thuringiensis plcR regulon and for virulence. Mol Microbiol 200I, 40(4):963-975.

10. Slamti L, Lereclus D: A cell-cell signaling peptide activates the PIcR virulence regulon in bacteria of the Bacillus cereus group. Embo J 2002, 2 I ( I 7):4550-4559.

II. Hoch JA: Two-component and phosphorelay signal transduction. Curr Opin Microbiol 2000, 3(2): 165-170.

12. Alm E, Huang K, Arkin A: The evolution of two-component systems in bacteria reveals different strategies for niche adaptation. PLoS Comput Biol 2006, 2(I I):el43.

13. Galperin MY: A census of membrane-bound and intracellular signal transduction proteins in bacteria: bacterial IQ, extroverts and introverts. BMC Microbiol 2005, 5:35.

14. Anderson I, Sorokin A, Kapatral V, Reznik G, Bhattacharya A Mikhailova N, Burd H, Joukov V, Kaznadzey D, Walunas T, et al: Comparative genome analysis of Bacillus cereus group genomes with Bacillus subtilis. FEMS Microbiol Lett 2005, 250(2): $175-184$.

15. Ivanova N, Sorokin A, Anderson I, Galleron N, Candelon B, Kapatral V, Bhattacharyya A, Reznik G, Mikhailova N, Lapidus A, et al: Genome sequence of Bacillus cereus and comparative analysis with Bacillus anthracis. Nature 2003, 423(6935):87-91.

16. de Been M, Francke C, Moezelaar R, Abee T, Siezen RJ: Comparative analysis of two-component signal transduction systems of Bacillus cereus, Bacillus thuringiensis and Bacillus anthracis. Microbiology 2006, I 52(Pt I0):3035-3048. 
17. Duport C, Zigha A, Rosenfeld E, Schmitt P: Control of enterotoxin gene expression in Bacillus cereus F4430/73 involves the redox-sensitive ResDE signal transduction system. J Bacterio 2006, I 88( I 8):6640-665|

18. Fagerlund A, Brillard J, Furst R, Guinebretiere MH, Granum PE: Toxin production in a rare and genetically remote cluster of strains of the Bacillus cereus group. BMC Microbiol 2007, 7(I):43.

19. Aguilar PS, Hernandez-Arriaga AM, Cybulski LE, Erazo AC, de Mendoza $D$ : Molecular basis of thermosensing: a two-component signal transduction thermometer in Bacillus subtilis. Embo J 200I, 20(7): I68I-I69|.

20. Jordan S, Junker A, Helmann JD, Mascher T: Regulation of LiaRSdependent gene expression in Bacillus subtilis: identification of inhibitor proteins, regulator binding sites, and target genes of a conserved cell envelope stress-sensing two-component system. J Bacteriol 2006, I 88( I4):5I53-5I66.

21. Ohki R, Tateno K, Okada Y, Okajima H, Asai K, Sadaie Y, Murata M, Aiso T: A bacitracin-resistant Bacillus subtilis gene encodes a homologue of the membrane-spanning subunit of the Bacillus licheniformis ABC transporter. J Bacteriol 2003, I 85( I):5 I-59.

22. Szurmant H, Mohan MA, Imus PM, Hoch JA: YycH and Yycl interact to regulate the essential YycFG two-component system in Bacillus subtilis. I Bacteriol 2007, I 89(8):3280-3289.

23. Yamamoto H, Murata M, Sekiguchi J: The CitST two-component system regulates the expression of the Mg-citrate transporter in Bacillus subtilis. Mol Microbiol 2000, 37(4):898-912.

24. Guinebretiere MH, Thompson FL, Sorokin A, Normand P, Dawyndt $P$, Ehling-Schulz M, Svensson B, Sanchis V, Nguyen-The C. Heyndrickx $M$, et al.: Ecological diversification in the Bacillus cereus Group. Environ Microbiol 2008, I 0(4):85 I-865.

25. Lapidus A, Goltsman E, Auger S, Galleron N, Segurens B, Dossat C Land ML, Broussolle V, Brillard J, Guinebretiere MH, Sanchis V, Nguen-The C, Lereclus D, Richardson P, Wincker P, Weissenbach J, Ehrlich SD, Sorokin A: Extending the Bacillus cereus group genomics to putative food-borne pathogens of different toxicity. Chem Biol Interact 2008, I 7 I (2):236-249.

26. Fabret $C$, Feher VA, Hoch JA: Two-component signal transduction in Bacillus subtilis: how one organism sees its world. J Bacteriol 1999, I8I(7): 1975-1983.

27. Grebe TW, Stock JB: The histidine protein kinase superfamily Adv Microb Physiol 1999, 4 I: I 39-227.

28. Gohar M, Faegri K, Perchat S, Ravnum S, Økstad OA, Gominet M Kolstø $A B$, Lereclus $D$ : The PIcR virulence regulon of Bacillus cereus. PLOS ONE 2008:e2793.

29. Gohar M, Gilois N, Graveline R, Garreau C, Sanchis V, Lereclus D: A comparative study of Bacillus cereus, Bacillus thuringiensis and Bacillus anthracis extracellular proteomes. Proteomics 2005 , 5( I 4):3696-37II.

30. Gilois N, Ramarao N, Bouillaut L, Perchat S, Aymerich S, Nielsen-Leroux C, Lereclus D, Gohar M: Growth-related variations in the Bacillus cereus secretome. Proteomics 2007, 7(I 0): I7| 19-1728.

31. Kristoffersen SM, Ravnum S, Tourasse NJ, Økstad OA, Kolstø AB, Davies W: Low Concentrations of bile salts induce stress responses and reduce motility in Bacillus cereus ATCC | 4579. J Bacteriol 2007, I 89( | 4):5302-53 I3

32. Esbelin J, Jouanneau Y, Armengaud J, Duport C: ApoFnr binds as a monomer to promoters regulating the expression of enterotoxin genes of Bacillus cereus. J Bacteriol 2008 in press.

33. Zigha $A$, Rosenfeld $E$, Schmitt $P$, Duport $C$ : The redox regulator Fnr is required for fermentative growth and enterotoxin synthesis in Bacillus cereus F4430/73. J Bacteriol 2007 I 89(7):2813-2824.

34. Eymann C, Homuth G, Scharf C, Hecker M: Bacillus subtilis functional genomics: global characterization of the stringent response by proteome and transcriptome analysis. J Bacteriol 2002, I 84(9):2500-2520.

35. Fulda S, Mikkat S, Huang F, Huckauf J, Marin K, Norling B, Hagemann $M$ : Proteome analysis of salt stress response in the cyanobacterium Synechocystis sp. strain PCC 6803. Proteomics 2006, 6(9):2733-2745

36. Nissom PM, Sanny A, Kok YJ, Hiang YT, Chuah SH, Shing TK, Lee YY, Wong KT, Hu WS, Sim MY, et al: Transcriptome and proteome profiling to understanding the biology of high productivity CHO cells. Mol Biotechnol 2006, 34(2): I25-140.
37. Pratt JM, Petty J, Riba-Garcia I, Robertson DH, Gaskell SJ, Oliver SG, Beynon RJ: Dynamics of protein turnover, a missing dimension in proteomics. Mol Cell Proteomics 2002, I (8):579-59I.

38. Beier D, Gross R: Regulation of bacterial virulence by twocomponent systems. Curr Opin Microbiol 2006, 9(2): I43-I52.

39. Altschul SF, Madden TL, Schaffer AA, Zhang J, Zhang Z, Miller W, Lipman DJ: Gapped BLAST and PSI-BLAST: a new generation of protein database search programs. Nucleic Acids Res 1997, 25(I 7):3389-3402.

40. Letunic I, Copley RR, Schmidt S, Ciccarelli FD, Doerks T, Schultz J, Ponting CP, Bork P: SMART 4.0: towards genomic data integration. Nucleic Acids Res 2004:DI42-I44.

4I. Schultz J, Milpetz F, Bork P, Ponting CP: SMART, a simple modular architecture research tool: identification of signaling domains. Proc Natl Acad Sci USA 1998, 95(I I):5857-5864.

42. Bailey TL, Elkan C: Fitting a mixture model by expectation maximization to discover motifs in biopolymers. Proc Int Conf Intell Syst Mol Biol 1994, 2:28-36.

43. Bouillaut L, Ramarao N, Buisson C, Gilois N, Gohar M, Lereclus D, Nielsen-Leroux C: FlhA influences Bacillus thuringiensis PIcRregulated gene transcription, protein production, and virulence. Appl Environ Microbiol 2005, 7 I ( I 2):8903-89l0.

44. Lereclus $D$, Arantes $O$, Chaufaux J, Lecadet $M$ : Transformation and expression of a cloned delta-endotoxin gene in Bacillus thuringiensis. FEMS Microbiol Lett I989, 5 I ( I):2 I I-2I7.

45. Arnaud $M$, Chastanet $A$, Debarbouille $M$ : New vector for efficient allelic replacement in naturally nontransformable, low-GCcontent, gram-positive bacteria. Appl Environ Microbiol 2004 70( I I):6887-689I.

46. Guerout-Fleury AM, Shazand K, Frandsen N, Stragier P: Antibioticresistance cassettes for Bacillus subtilis. Gene 1995, I67(I2):335-336

47. Trieu-Cuot P, Courvalin P: Nucleotide sequence of the Streptococcus faecalis plasmid gene encoding the 3'5"-aminoglycoside phosphotransferase type III. Gene I983, 23(3):33I-34I.

48. Agaisse $H$, Lereclus $D$ : Structural and functional analysis of the promoter region involved in full expression of the cryIIIA toxin gene of Bacillus thuringiensis. Mol Microbiol 1994, I3(I):97-107.

49. Pfaffl MW: A new mathematical model for relative quantification in real-time RT-PCR. Nucleic Acids Res 2001, 29(9):e45.

50. Heukeshoven J, Dernick R: Improved silver staining procedure for fast staining in PhastSystem Development Unit. I. Staining of sodium dodecyl sulfate gels. Electrophoresis I988, 9(I):28-32.

5I. Neuhoff V, Arold N, Taube D, Ehrhardt W: Improved staining of proteins in polyacrylamide gels including isoelectric focusing gels with clear background at nanogram sensitivity using Coomassie Brilliant Blue G-250 and R-250. Electrophoresis 1988, 9(6):255-262.

52. Faurobert M, Mihr C, Bertin N, Pawlowski T, Negroni L, Sommerer $N$, Causse $M$ : Major proteome variations associated with cherry tomato pericarp development and ripening. Plant Physiol 2007, I 43(3): | 327-I346.

53. Perkins DN, Pappin DJ, Creasy DM, Cottrell JS: Probability-based protein identification by searching sequence databases using mass spectrometry data. Electrophoresis 1999, 20( I 8):355I-3567.

54. Ramarao N, Lereclus D: The InhAl metalloprotease allows spores of the $B$. cereus group to escape macrophages. Cell Microbiol 2005, 7(9): | 357-| 364.

55. Finney DJ: Probit Analysis. London: Cambridge University Press; I97I.

56. Raymond M, Prato G, Ratsira D: PROBIT analysis of mortality assays displaying quantal response. Saint Georges d'Orgue, France: PRAXEME; 1993

57. Corpet F: Multiple sequence alignment with hierarchical clustering. Nucleic Acids Res 1988, I 6(22): I088I-10890.

58. Arantes $O$, Lereclus $D$ : Construction of cloning vectors for Bacillus thuringiensis. Gene I99|, I08(I):।I5-II9. 